\title{
Online Shopping in a Restrictive Society: Lessons from Saudi Arabia
}

\begin{abstract}
Purpose - Western consumers are able to take shopping for granted, their major restriction being financial. This research aims to understand motivations to buy fashion items online in the culturally restrictive environment of Saudi Arabia, which imposes considerable fashion and behavioural restrictions, particularly on females.
\end{abstract}

Design/methodology/approach - Qualitative research was conducted with a sample of 34 Saudi women in their home country providing a deep insight into the restrictions that women face when shopping and how they react to these restrictions. Two theoretical lenses, psychological reactance and system justification theories, are invoked to understand and explain consumer behaviour.

Findings - Motives for online shopping are quite different in a restrictive society. The definition of utilitarian motivations in online shopping is developed to reflect the drivers to overcome cultural restrictions or to align one's shopping behaviour with them. Similarly, hedonic reasons for online purchase are expanded to incorporate nuances found only in such societies, where hedonic motivations include enjoying the breaking of societal restrictions.

Originality/value - This research is conducted is focussed on a country in which little academic marketing research has taken place due to considerable restrictions on movement and access. Western texts on consumer behaviour are not fully appropriate for understanding such a society.

Keywords - Online shopping; consumer behaviour in restrictive societies; Saudi Arabia;

Paper Type - Research Paper 
Introduction

Our understanding of marketing and consumer behaviour comes largely from Western texts. The contribution of this paper is to explore motivations to purchase (fashion items online) in Saudi Arabia, a restrictive society dominated by a religious culture, which drives laws and social perceptions regarding how citizens live, buy and dress. The literature studying motivations of shopping for fashion online has developed as we have moved from the era of clicks or bricks to omnichannel retailing where the customer expects a seamless shopping experience across the differing channels (Sebald and Jacob, 2019). Grewal, Roggeveen, and Nordfält (2017) discuss the blurring of the lines between channels as a result of the digitalization of retailing. Hagburg, Sundstrom, and Egels-Zandén (2016) discuss the innovations that have changed fashion shopping including avatars, virtual showrooms and systems that automatically recommend items to the consumer to curated fashion retailing, combining the benefits of online and offline shopping (Sebald and Jacob, 2019).

Unsurprisingly, consumer behaviour has become more sophisticated as multiple channels have developed. Examples include webrooming (where the consumer searches for information online but purchases offline) (Flavián, Gurrea and Orus, 2016) and showrooming (the opposite; buying online having searched physical stores (Neslin, et al, 2014) have become common practices in omnichannel consumer behaviour. All this, however, assumes the consumer is perfectly able to make their choices unhindered by anything other than possibly the limitations of their own budget. Are motivations similar when state-imposed restrictions are an important part of life? Fashion related e-commerce sales in Saudi totalled $\$ 383.1 \mathrm{~m}$ in 2019 and is forecasted to rise to $\$ 469 \mathrm{~m}$ by 2024 (Statista.com 2020). Saudi Arabia contributed the largest amount (\$3bn) to online sales of $\$ 8.3$ bn from the MENA countries in 2017, growth having increased annually by $25 \%$ p.a. since 2014 (Fabre, Malauzat, Sarkis, Dhall, \& Ghorra, 2019. In developing and emerging 
markets, national income is usually a main determinant of the ability and desire to buy fashion internationally online (Talukdar, Sudhir and Ainslie, 2002). However, Saudi Arabia has a higher GDP per capita than large European Economies such as the UK, France and Germany yet per capita online fashion spend is only the $56^{\text {th }}$ highest in the world (Statista.com 2020). Therefore, there is considerable room for expansion of online retailing. Thus, there is interest for both academics and practitioners in how choices are made in Saudi Arabia's particular cultural context. The World Economic Forum (2018) ranked Saudi Arabia 141st of 149 countries for gender equality. Saudi women face restrictions unlike those in any other country. Under laws enforced by the religious police, they may not vote in elections, wear makeup, or be unaccompanied in public (Deif, 2008; Greenberg, 2014), and until very recently Saudi Arabia was the only country in the world where women were forbidden to drive. As an example of the radical difference between the market for fashion between Saudi and Western cultures, a law was passed in June 2015 banning fashion shows in Saudi Arabia (Baamer, 2015; Variyar, 2015).

This paper demonstrates that in a restrictive society, online shopping can afford women greater control of their shopping behaviour and provide a means to express their attitudes towards restrictions by buying clothes from abroad. No previous study has investigated online shopping motivations as reflecting and reacting to cognitive dissonance in restrictive societies. The research objectives are to define the restrictions, to facilitate an understanding of how attitudes towards them differ, and then to theorize differing online shopping motivations based on variation in attitudes (accepting versus rejecting) to the restrictions. Finally, we wish to add to the literature by presenting an alternative perspective on online shopping motivations to the dominant Western-centric view. 


\section{Literature Review}

\subsection{Islamic fashion and motivations to buy fashion online}

Although literature based upon Western experience and consumer behaviour dominates existing research, there has been more recent consideration of fashion shopping in Islamic markets. For example, Hassan and Harrun (2016) discuss hijab fashion, where the hijab itself becomes a central component of fashion. Stacey (2009) details the rise of Islamic consciousness and the place of the hijab in this, post 9/11. Potts (2009) comments that many Muslim countries now embrace an Islamic cosmopolitanism that allows women to express themselves by use of different styles, bold colours etc. whilst not contravening their religious adherence. Of course, Muslims live in many countries and societies where different standards will apply. Hassan and Harrun's work (2016) is based in Malaysia which, although a Muslim country, does not make wearing of the hijab compulsory. Perhaps this has led to what they describe as habijista women and a Muslimah image. Although Islam may provide a complete world view there are considerable differences in lifestyle and interpretation. Qatar is a wealthy country and there is considerable expenditure on luxury brands. Kassim and Zain, (2015) discuss the materialism within Qatari consumption. Farrag and Hassan (2015) talk of the desire to show off being condemned in Islam but that there is a growing number of fashionconscious Muslim consumers; they highlight the incongruity between Islamic identity and the purchase of fashion goods, making this an interesting area to study.

When it comes to online shopping the two main motivations are utilitarian and hedonic (Arnold \& Reynolds, 2003). Utilitarian shopping is described as task-related, rational and centred on practical and objective perspectives (for example, quality and convenience) (Griffin, Babin and Modianos, 2000; Lim, 2014), described as "shopping as work" (Babin, Darden and Griffin, 1994). Products are purchased because they are needed, rather than to enjoy shopping itself (Scarpi, Pizzi \& Visentin, 2014). Babin et al., (1994) affirm that such 
shopping is deliberate; decisions are carefully evaluated and efficient. This perspective treats the consumer as a logical problem solver (Sarkar, 2011). Widespread internet access makes online shopping easy and convenient at any time.

Hedonic shoppers, by contrast, seek pleasure in shopping (To and Sung, 2015; Compeau, Monroe, Grewal and Reynolds, 2015). Enjoyment and expressive value can be felt and enjoyed by interacting with a situation when shopping. Arnold and Reynolds, (2003), identify types of hedonic shopping motivation, including adventure (seeking difference or stimulation), gratification (shopping to mitigate stress), role (providing gifts or pleasure to others), value (the enjoyment of finding bargains and discounts), social (maintaining or enhancing relations) and idea shopping (getting to know new trends and products). Hedonic motivations also embrace feelings of freedom (Wolfinbarger and Gilly, 2001) and of authority and status conferred by customised services and recommendations (To, Liao and Lin, 2007).

However, again, this literature naturally takes a Western standpoint. In emerging and especially in restrictive environments such as Saudi Arabia, these hedonic and utilitarian motivations may be questioned. Given the restrictions applied to Saudi women in public, shopping offline presents many challenges which may encourage them to shop online instead. Indeed, their motivation to shop online is expected to be different from women in more liberal countries.

\subsection{Theories underpinning motivation in restrictive environments}

The enforcement of conformity is the single most important means by which cultural factors affect consumer behaviour in any environment. Thus, socio-psychological theorists state that aspiring to conformity pushes people to echo the behaviour of their peer group, corresponding to societal norms (Göbel, Schneider and Thomas, 2010). Conversely, there is potential for actively resisting cultural norms, particularly when individuals feel pressure to conform, 
causing more active resistance (Venkatesan, 1966). Personal needs for adjustment to conformity generally affect customers' attempts to create different consumption styles (Hemetsberger and Weinberger, 2012). However, desire for autonomy can lead consumers to actively resist and reject cultural norms. In Saudi Arabia, high cultural pressure to conform, particularly for women, may increase the potential for resistance, as exemplified by those who openly challenge the restrictive norms against female entrepreneurship (Welsh, Memili, Ouchi and Kaciak, 2014).

In countries where freedom of choice is restricted, individuals' employ coping mechanisms and we suggest reactions can be predicted by two theories: system justification theory (SJT), which deals with rationalising restrictions, and psychological reactance theory (PRT), referring to attempts by individuals to break restrictions (Kay, Gaucher, Napier, Callan and Laurin, 2008; Laurin, Kay and Fitzsimons, 2012). Laurin, Kay, Proudfoot and Fitzsimons, (2013) describe the rationalization of perceived restrictions as a range of psychological processes designed to make a particular restriction appear more attractive to the person rationalising it. For instance, cognitive dissonance theory has shown that people move broadly towards preserving a view of their behaviour as aligned with their preferences, usually by refining the perceived need for a decision already taken or an action already performed (Cooper, 2007).

Similarly, SJT sees people as driven to expand the validity of the system under which they live (Jost, Banaji and Nosek, 2004), recognising the status quo as desirable (Kay, Gaucher, Peach, Laurin, Friesen, Zanna and Spencer, 2009), even those rules that they may disagree with. The clearest demonstration of this is the explicit confirmation of ideologies that serve to legitimize existing social, economic and political arrangements (Jost and Hunyady, 2003). Those who believe strongly in a religion, for example, see its restrictions as guaranteeing their security and safety (Kadirov, Allayarova and Boulanouar, 2016). Strongly religious people 
also tend to be more assertive (Altemeyer 2002, Francis, 2001), less tolerant of inconsistency and ambiguity (Budner, 1962), more accepting of personal control (Hood, Spilka, Hunsberger and Gorsuch, 1996) and relatively resistant to new experiences (Saroglou, 2002). Therefore, religious people may tend to justify social, religious and legal restrictions in their lives. SJT theory embraces the concept that there is a subgroup of belief systems that grants moral and intellectual validity to the status quo. Working instances of system-justifying belief systems in modern Western civilizations are "faith in a just world, the Protestant work ethic, fair market ideology, opposition to equality, right-wing authoritarianism and political conservatism." (Jost and Hunyady, 2005, p.260). System justification is motivated in part by the epistemic need to reduce uncertainty and ambiguity; research consistent with this assertion associates the personal desire for law, structure and termination with the endorsement of conservative, system-justifying attitudes.

Conversely, PRT holds that individuals are driven to restore usurped liberties and resist attempts to be coerced (Brehm, 1966; Wicklund and Brehm, 1976). Psychological reactance theory posits that certain individuals will have an entirely contrary response to limitations on their freedom to that predicted by system justification theory (Brehm, 1966). PRT suggests that individuals are driven to replace defunct liberties and respond undesirably to attempts by others to coerce their freedom (Wicklund and Brehm, 1976). Thus, restricting freedom is counterproductive for certain individuals. According to PRT, when a reactant consumer receives a recommendation to purchase a certain product, she feels constrained from choosing other, seemingly more desirable products (Kwon and Chung, 2010; Lee, Lee and Sanford, 2010). This can engender reactance against the recommended product, less confidence in the recommendation and a greater attraction towards non-recommended products (Kwon and Chung, 2010). So, individuals can place greater worth on objects or opinions that their background or society denies them. Knight et al. (2014) conclude that highly reactive people 
are anti-system rebels. However, no known published literature has shown how online shopping can reflect consumer reactance to current social, legal or religio-legal restrictions.

Thus, we suggest that those who believe in restrictions or the need for them behave so as to justify them, whereas the behaviour of those who disbelieve in them reflects their psychological rejection of them. So, in Saudi society where women's freedom as consumers is considerably constrained, SJT and PRT can assist us in understanding consumer behaviour. Thus, figure 1 represents a conceptual framework for understanding Saudi women's motivations in shopping online. In a hierarchical society like Saudi, it could be assumed that there would be a strong leaning toward SJT. However, those exhibiting PRT may escape restrictions via online shopping. So, we posit that the two theories can help explain consumers' attitudes towards the restrictions, thus leading to their motivations to either justify or react against the restrictions and then demonstrated by their actual behaviour. This is detailed in figure 1 .

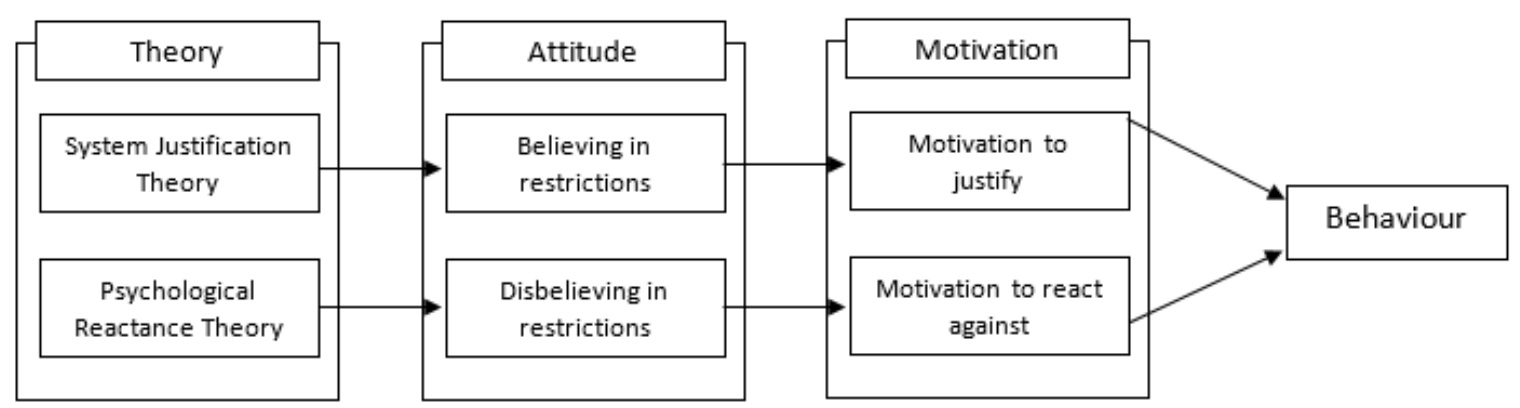

Figure 1: Conceptual framework 


\section{Methodology}

\subsection{Sampling}

We wished to recruit women from a restrictive society who had the means and ability to shop online, to allow qualitative investigation of their attitudes, motivations and behaviours regarding online shopping. The population targeted was Saudi women resident in Saudi Arabia, able to buy fashion online without restrictions of a psychological (trust in online shopping; perceived difficulties in buying fashion online) or physical nature (shipping or payment problems). Men were excluded because women face considerably more restrictions, specifically in choice of clothing (Al-Rasheed, 2013). The age range (30-49) was selected to exclude both young and old. Older people are more inclined to justify the status quo (Kay et al., 2009), while teenagers and young women may experience greater control by their families or be sensitive to peer pressure (imitating friends, celebrities or fashion icons) in their fashion behaviour (Parker, Hermans and Schaefer, 2004; Khare, Parveen and Mishra, 2012). All recruits had experience in online shopping and bought fashion, clothes and other items online. To ensure consistency, avoiding the effects on attitude of living in remote or rural areas $(\mathrm{Xu}$ and Paulins, 2005), all interviews were conducted in Riyadh. An interview guide had been produced following an initial focus group (eight participants) that discussed the restrictions that women face shopping in Saudi. This allowed us to identify three main areas for investigation. First, perceptions of fashion restrictions in Saudi and respondents' attitudes towards them; second the consequences of the restrictions on the motivations of respondents and then third, how this affected their actual behaviour in online shopping. The interview guide was revised by four academics and then tested on three Saudi women to ensure understanding.

The criteria for sample selection and size were set by the iterative nature of the data collection and analysis by theoretical sampling (Charmaz, 2006; Ong, 2012). Snowballing was used due 
to the difficulty in accessing an appropriate sample in such a restrictive society. Initial telephone discussions with potential respondents took place to ensure that a respondent met our criteria. It was not easy to address all imposed restrictions with Saudi women, especially those who opposed them. Despite assured anonymity, two respondents found the research too sensitive and withdrew, leaving a final sample of 34 completed interviews.

Acceptance of societal restrictions is a complex phenomenon and it was important that the sample represented a variety of views. To this end, a 'hijab index' was used to reflect the extent of each woman's acceptance of restrictions regarding her fashion style. Such an index has been used before to reflect the level of fashion religiosity (Tolaymat and Moradi, 2011; Swami, Miah, Noorani and Taylor, 2014). Its dimensions are the frequency of wearing a typical style of veiling or headwear and the level of its conservativeness. Our research modified the index to reflect strength of adherence to the restrictions imposed in Saudi Arabia, taking account of the level of conservativeness (extent of covering the body) and whether a woman changed her style when abroad, i.e. beyond enforcement. Thus, interviewees were coded on what they wore in the interview and on their responses when asked how they dressed abroad.

Table 1Table 1 shows a woman wearing the niqab (the highest level of conservativeness) even when abroad scores 'high', whilst 'medium' indicates wearing a niqab or hijab in the interview, but a hijab when travelling, and 'low' means no hijab, or wearing the hijab in Saudi Arabia only. In the coding used to identify participants anonymously, the first letter $(\mathrm{H}, \mathrm{M}$ or L) represents the hijab index score and the second is the first letter of the respondent's name. 17 respondents were classified as high, 9 as medium and 8 as low according to the hijab index. 


\begin{tabular}{|c|c|c|c|}
\hline & In interview & $\begin{array}{l}\text { Outside Saudi } \\
\text { Arabia }\end{array}$ & Examples* \\
\hline High & Niqab & Niqab & \\
\hline Medium & Niqab or hijab & Hijab & \\
\hline Low & Unveiled or hijab & Unveiled & \\
\hline
\end{tabular}

\subsection{Data analysis}

Data were analysed thematically (Alhojailan, 2012) using three coding methods (Charmaz, 2006). Closed coding searches for known phenomena, using theory as a sensitising tool, open coding seeks to understand new themes and axial coding connects data between codes (Glaser and Strauss, 2009). Open and axial coding is used for discovering new patterns and developing the theory. The coding process was developed on the basis of the conceptual framework (Lee and Hubona, 2009) outlined in figure 1. Closed coding was used to classify interviewees as reacting to or justifying restrictions and by intensity of online fashion shopping.

Manual (open) coding was used first to identify themes when screening interview transcripts, based upon the theoretical framework of SJT and CRT. This analytical approach is aligned with the abductive approach of using theories and empirical data together to develop new theory (Dubois and Gadde, 2002). Then NVIVO10 was used for automated (selective) coding. Themes were developed considering two criteria: the number of interviewees mentioning them and the time that respondents devoted to them (Braun and Clarke, 2006; Wao, Dedrick and Ferron, 2011) and then when finalised by the research team during the analysis of the data. Any specific point repeated more than four times was subjected to further analysis (Dubois and Gadde, 2002), based on the sample size of 34. We set benchmarks to 
assist us analyse the large amount of data and combined this with our own intuition to formulate the final themes. Looking at the numbers of respondents who specifically discussed a certain topic and the time devoted to the topic allowed us to make some initial judgements for further analysis.

If three respondents mentioned an area of interest, it was considered for analysis only if they spent on average at least 10 minutes discussing it, the rationale being the interviews averaged an hour and had to cover three main topics. With a smaller number of respondents detailing a topic we needed evidence that there was significance resonance to the respondent in order to justify further analysis (Braun and Clarke, 2006). . Devoting a significant part of the interview to a subject demonstrated its resonance.

As analysis continued, themes were agreed amongst the research team. Transcripts were checked for narrative accuracy and for consistency of interpretive, descriptive, theoretical and evaluative validity among the authors. Accuracy was first checked by the researcher summarising each response when made and confirming with the respondent that this was what she meant. Theoretical validity was checked by continuous examination of the findings to determine whether they were aligned with the literature. Coding reliability was ensured by cross-matching samples of codes among the research team; codes agreed by three or more of us were recognized and considered. Specifically, the research team interpreted the interview transcripts individually, making notes, then our separate interpretations were cross-referenced, allowing us to narrow down the data into key themes and we were able to collapse themes into the final set, eliminating repetition enabling us to best use the stories and perspectives of our respondents to create the most parsimonious set of themes to interpret the theory as an approach to understanding consumer behaviour in a restrictive environment. 


\section{Findings and Analysis}

Figure 2Figure 2 summarises the findings. The definition, perception and attitude towards different fashion restrictions are scoped (section 3.1), and then the consequences of these perceptions and attitudes are examined using PRT and SJT (3.2). Twenty-one respondents justified the restrictions, fewer showed evidence of psychological reactance. In section 3.3, these understandings are applied to participants' online fashion shopping, translating the consequences of attitudes and perceptions into motivations and behaviours. Sixteen women were coded as utilitarian, six as hedonic and twelve as both.

\begin{tabular}{|l|}
\hline Matching versus \\
mismatching between \\
religious restrictions (self- \\
interpreted) and externally \\
enforced restrictions \\
\hline
\end{tabular}

\section{Perception of restrictions (Section 3.1)}

Religious restrictions $\rightarrow$

Self-interpretation

Religio-legal

restrictions $\rightarrow$ Religious

police enforcement

Social

restrictions $\rightarrow$ Family and

peer norms

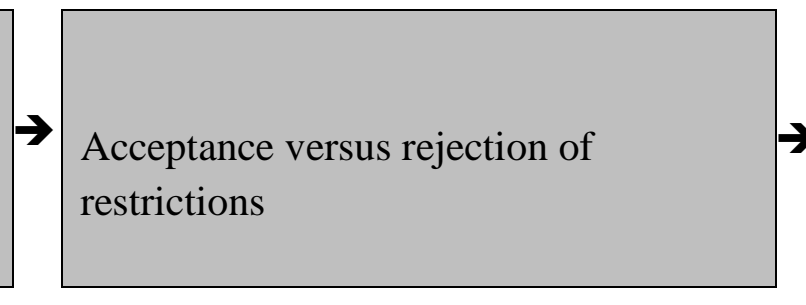

Reacting versus justifying attitude (Section 3.2)

Because the restriction is accepted, it is accommodated $\rightarrow$ Justifying behaviour

Because the restriction is rejected, it is disobeyed $\rightarrow$ Psychological reactance

behaviour

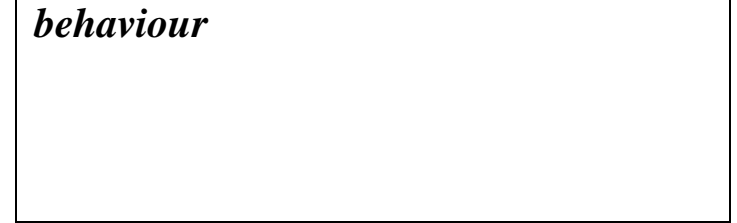

Figure 2: Summary of findings
Motivations

to buy vary

to buy vary

Motivations

to buy (3.3)

Utilitarian

motivation

Hedonic

motivation

\subsection{Perceptions of fashion restrictions}

Cultural restrictions in Saudi Arabia were interpreted as (a) religious, (b) religio-legal (enforced by the religious police) and (c) social. Religious restrictions limit each woman's freedom in line with her own interpretation of the Qur'an and the Hadith (the words of Prophet Mohammed). Religio-legal restrictions are embodied in the actions of the religious police, 
who patrol public areas and challenge those they consider inappropriately dressed, based on the state's interpretation of Islamic sources. Finally, social restrictions on freedom reflect how society interprets them. These factors combine to build cultural restrictions. Table 2 shows their alignment with dress code requirements.

Table 2: Dress code restrictions

\begin{tabular}{|l|l|l|}
\hline Concept & Definition & $\begin{array}{l}\text { Dress code criteria based on } \\
\text { respondents }\end{array}$ \\
\hline $\begin{array}{l}\text { Religious } \\
\text { restrictions }\end{array}$ & $\begin{array}{l}\text { Individual interpretation of the Qur'an } \\
\text { and Hadith }\end{array}$ & $\begin{array}{l}\text { No fixed criteria, but respondents } \\
\text { all agree the hijab is required }\end{array}$ \\
\hline $\begin{array}{l}\text { Religio-legal } \\
\text { restrictions }\end{array}$ & Interpretation by the religious police & $\begin{array}{l}\text { Criterion is the niqab (covering the } \\
\text { face, hair and body) }\end{array}$ \\
\hline $\begin{array}{l}\text { Social } \\
\text { restrictions }\end{array}$ & Family and friends' interpretations & $\begin{array}{l}\text { Dependent on family background. } \\
\text { Criteria are not fixed }\end{array}$ \\
\hline
\end{tabular}

The same restrictions were interpreted differently by respondents (Table 3). Religious and social restrictions were neither fixed nor clear-cut, being based on scriptural interpretation. For instance, exactly half of respondents considered the niqab an Islamic requirement.

Table 3: Respondents' interpretations of female dress restrictions in Saudi Arabia

\begin{tabular}{|c|c|c|c|}
\hline Restriction & Niqab & Hijab & Unveiled/uncovered hair \\
\hline Social & $\begin{array}{l}\text { Society imposes a strict } \\
\text { requirement on women to } \\
\text { wear the niqab: } \\
\text { Uncovering the face is not } \\
\text { forbidden and we know it's } \\
\text { accepted. Religion eases our } \\
\text { lives rather than making } \\
\text { them difficult. However, our } \\
\text { society makes it a must and it } \\
\text { becomes more of a national } \\
\text { tradition than a religious } \\
\text { requirement. } 10 \mathrm{HH}\end{array}$ & $\begin{array}{l}\text { Society imposes a strict } \\
\text { requirement on women } \\
\text { to wear the hijab: } \\
\text { I'm not forced to wear it. } \\
\text { But I know they are } \\
\text { intolerant of this } \\
\text { behaviour and I respect } \\
\text { that. } 20 \mathrm{LZ}\end{array}$ & $\begin{array}{l}\text { The family pressurises } \\
\text { members to be unveiled } \\
\text { or liberal: } \\
\text { I don't wear the hijab. I } \\
\text { was forced to take it off } \\
\text { [by husband and his } \\
\text { family]. I don't claim that } \\
\text { I have no responsibility } \\
\text { for doing this. I'm sure, if } \\
\text { I insisted on wearing it, I } \\
\text { could do so even if I faced } \\
\text { difficulties. 03LA }\end{array}$ \\
\hline $\begin{array}{r}\text { Religio- } \\
\text { legal }\end{array}$ & \multicolumn{3}{|c|}{ Women must wear the niqab in public places in Saudi Arabia. } \\
\hline Religious & $\begin{array}{l}\text { One interpretation is that } \\
\text { the niqab must/should be } \\
\text { worn: } \\
\text { Nothing is called a hijab; } \\
\text { these people misinterpret }\end{array}$ & $\begin{array}{l}\text { Interpretation that the } \\
\text { hijab is compulsory: } \\
\text { The hijab is a [religious] } \\
\text { constraint. I don't wear it } \\
\text { often. When I do wear it, I }\end{array}$ & $\begin{array}{l}\text { Interpretation that the } \\
\text { niqab and hijab are not } \\
\text { necessary: } \\
\text { To be a Muslim it's not } \\
\text { necessary to cover your }\end{array}$ \\
\hline
\end{tabular}




\begin{tabular}{|l|l|l|}
\hline $\begin{array}{l}\text { the Qur'anic phrase. It is } \\
\text { the niqab, not the hijab that } \\
\text { is a must. } 19 \mathrm{HH}\end{array}$ & $\begin{array}{l}\text { pretend that I'm a good } \\
\text { Muslim. 03LLA }\end{array}$ & $\begin{array}{l}\text { hair and it doesn't mean } \\
\text { that you will lose your } \\
\text { rights in society. I can do } \\
\text { anything I want. 21LHB }\end{array}$ \\
\hline
\end{tabular}

\subsection{Reacting versus justifying behaviour}

Attitudes varied as a result of the differences in what was accepted under the three different kinds of restrictions. When (self-interpreted) religious restrictions differed from those imposed by family and friends or the state, the woman's behavioural response was either to accept the restrictions (SJT) or to react against them (PRT). Her consequent behaviour was based on her attitude towards the enforcement of the restrictions. In other words, when the religious restrictions were matched the religio-legal ones, the attitude was to accept and therefore to justify them, as exemplified by this explanation of a woman who always wore a niqab in public:

There is no such thing as a hijab; these people misinterpret the Qur'anic phrase. It is the niqab, not the hijab that is compulsory ... The religious police are actually right. They are doing a very good job to protect our society. $19 \mathrm{HH}$

Conversely, when the state's interpretation conflicted with a woman's self-interpretation, her attitude towards the restrictions was negative and she tended to rebel against them:

I don't believe the niqab is a religious requirement. I feel it is a barbaric traditional requirement; there are different Qur'anic interpretations of fashion-related verses. 03LA

Social and religious definitions of acceptable behaviour varied among individuals and families, whereas religio-legal restrictions were seen as fixed but both were relevant in leading to their acceptance (SJT) or rejection (PRT).

\subsection{Motivations to buy online}


Women who justified the religio-legal and social restrictions (exhibiting SJT) were motivated to adopt different online shopping behaviours from those who psychologically reacted against these restrictions (exhibiting PRT). Those justifying restrictions were more inclined to focus on utilitarian motivations to shop, whereas women psychologically opposed to them were more hedonically motivated to shop online by the enjoyment of breaking them.

Religious women may shop hedonically online, but the systems justification theory helps us understand how their motivations differ from those who react against the restrictions. Regardless of religiosity or attitude towards fashion restrictions, there is a value motivation to distinguish oneself from others; however, less religious respondents indicated their desire to break free of restrictions by buying online from Western sources, whereas highly religious women did not seek or gain this satisfaction. Women exhibiting system justification were more aligned with, and likely to defend traditions, social norms and religious restrictions, whereas psychologically reactant women actually enjoyed breaking the restrictions. Moreover, the more religious women made assertions that reinforced societal norms e.g. stating markets are not recommended for women and thus rationalised their inability to shop alone. So, SJT helps us understand their attitudes and their motivation to shop is utilitarian with the internet there to help overcome a woman's restriction of movement. Table 4 summarises motivational themes and subthemes, examined further below.

Table 4: Themes and subthemes of motivation

\begin{tabular}{|l|ll|}
\hline Themes & Subthemes \\
\hline \multirow{3}{*}{ Utilitarian motivation } & $-\quad$ Difficulties of going to market alone \\
& $-\quad$ Markets are not recommended for women \\
& $-\quad$ Buying products not available in the Saudi market \\
\hline Hedonic motivation & $-\quad$ Idea shopping (to discover new designs, to attach oneself \\
& $\begin{array}{l}\text { to liberal societies and to break the restrictions) } \\
-\end{array}$ \\
& Value shopping (to distinguish oneself).
\end{tabular}




\subsubsection{Utilitarian motivations}

The opportunity to shop at home offers great convenience to all consumers. Traditional utilitarian motivations were identified regardless of religiousness of dress and whether social and religio-legal restrictions were justified or rejected. Nevertheless, they were likely to be dominant for women who justified the social and religio-legal restrictions than for those who rejected them. Online shopping offers a wide range of alternative products more cheaply, easily and quickly than by visiting physical shops. Indeed, this offers an opportunity for high religiosity women to shop without contradicting the restrictions on them (SJT).

I used to waste a lot of time walking from here to there in the congested markets ... looking for my size. Now online shopping really makes life easier. $04 \mathrm{HN}$

Although this would be the case in any society, the definition of utilitarian motivation is extended by understanding it through the lens of Systems Justification Theory to cover three additional aspects: difficulties in going shopping alone, the religious belief that markets are not recommended for women, and buying clothes that are not available in Saudi Arabia.

\subsubsection{Going Shopping Alone}

Saudi law forbids women to take taxis unaccompanied and has only recently permitted women drivers. The driving ban was a country-specific religio-legal restriction reflecting the restrictive culture.

In order to buy offline, a woman has to ask her husband, brother or son to chaperone her to the shops. Consequently, one reason for buying online is the difficulty that Saudi women face when they want to shop, given the illegality of travelling unaccompanied:

The internet is better and more convenient for me than traditional shopping. Finding someone to give me a lift to the market is not easy at all. $19 \mathrm{HH}$ 
My family have always prevented me from shopping alone ... They require my husband or brother to go with me.17HA

...problems with transport in Riyadh... If you don't have a personal driver you're not allowed to take a taxi because it's unsafe in Saudi Arabia. 21LB

I love [online shopping] more than TV. Many families don't approve of their women going out alone [or even] going shopping at all. I believe online shopping would be helpful for all of them. $31 \mathrm{MW}$

Even those who rejected the constraints as laws from the "dark ages" had no option other than to adapt their behaviour accordingly:

When I was in the UK, transportation was easy; I could go or drive anywhere easily. In Saudi Arabia, it's very difficult for me as a woman to buy things offline for myself. Many times, I've begged any male of my family to give me a lift. Now with Amazon, I can go to millions of shops from home. 08MA

\subsubsection{Markets Not Recommended for Women}

According to a recent fatwa ${ }^{1}$ of an influential Saudi Islamic scholar, visiting markets is not recommended for women. Although such interpretations are not accepted by everyone (Hussein 1953; Ahmed 1992), many religious women in Saudi Arabia accept them. Our research found that highly orthodox women believed it would be wrong for them to visit markets. The following quotes highlight the relevance of SJT on attitudes, motivation and behaviour.

I don't like markets ... They're not recommended from the Islamic point of view because women and men mingle in one place. Lots of Islamic violations happen. Women are not properly dressed and talk goes on between males and females. 12HM

\footnotetext{
${ }^{1}$ The Urban Dictionary defines a fatwa as "any religious decision made by a mufti (Islamic scholar who is an interpreter or expounder of Islamic law)."
} 
Avoidance of the malls is sometimes encouraged male family members:

"My husband prefers [me] online shopping. He doesn't like me to go to traditional shops...this is normal in our culture. "23LHL

It was also clear that historical restrictions about women not being able to work freely were still very much in the mind of certain respondents:

"I strongly believe this point when it comes to lingerie. In Saudi, when only men were allowed to work in lingerie shops, I never went in." 11HLS

\subsubsection{Products Unavailable in Saudi Arabia}

Saudi Islamic scholars such as El Menajed ${ }^{2}$ believe that it is forbidden to produce or sell short skirts or women's trousers, because they might be worn in public. Therefore, Saudi producers are not willing to supply a wide variety of products and the scarcity leads some women to buy from foreign countries such as the UAE, Egypt, Turkey and Europe. Despite adopting a highly religious style of dress and claiming never to change it, 13HM stated that she went online to buy styles that were not available in Saudi Arabia. Beyond question, these items were not to be worn in public, but at women-only meetings and parties; she said that she would buy these products online because the Saudi market did not stock them in great variety.

I prefer online for buying fashions that are not available in the Saudi market [such as] T-shirts and trousers for our female meetings and parties. 13HM

Utilitarian motives included buying products with special characteristics such as very large sizes, or to meet particular contingencies such as scarcity in the offline market. The interviews reveal women's criteria for selecting clothing from the internet, making the choice of online

\footnotetext{
${ }^{2}$ http://islamqa.info/ar/102936
} 
shopping the result of the difficulty of finding what they wanted elsewhere (e.g. "my body is slight" or "I have thick bones").

In general, I don't like shopping online for fashion. However, sometimes I'm forced to. My daughter has special needs with her leg. It's not easy to find suitable clothes for her. This is my reason and motivation for buying online. 07HLN

\subsubsection{Hedonic Motivation}

The research found important lines of demarcation in hedonic motivation, because idea and value perspectives vary with religiousness of dress and the associated motivations (i.e. to justify or to react). Idea and value motivations, for those whose religious fashion criteria are aligned with social and religio-legal restrictions and who justify them, are restricted to buying fashion online for female-only meetings and parties. They use the internet to learn what is new in fashion by visiting websites based in Moslem countries or the accounts of key fashion influencers from Islamic countries, but do not visit Western websites or social network accounts.

Conversely, Psychological Reactance Theory helps explain why some react against the restrictions by attaching themselves to more liberal societies, breaking restrictions and distinguishing themselves from other Saudi women. Thus, such women were more likely to buy online from the West and not from Arab or Moslem countries. Table 5 distinguishes the hedonic motivations of women justifying fashion restrictions from those reacting against them. 
Table 5: Value versus idea motivation for those who justify versus those who react against restrictions

\begin{tabular}{|l|l|l|}
\hline & Idea & Value \\
\hline $\begin{array}{l}\text { System justification } \\
\text { (accepting } \\
\text { restrictions) }\end{array}$ & $\begin{array}{l}\text { To explore new designs from Arab } \\
\text { and Islamic countries }\end{array}$ & $\begin{array}{l}\text { To design fashions at their } \\
\text { accepted modesty level by } \\
\text { finding designers on } \\
\text { Instagram }\end{array}$ \\
\hline $\begin{array}{l}\text { Psychological } \\
\text { reactance (against } \\
\text { restrictions) }\end{array}$ & $\begin{array}{l}\text { To attach themselves to more liberal } \\
\text { societies by using the internet as a } \\
\text { window to these societies } \\
\text { To break the restrictions by buying } \\
\text { from non-Arab and non-Moslem } \\
\text { countries }\end{array}$ & $\begin{array}{l}\text { To distinguish themselves } \\
\text { from the rest of society }\end{array}$ \\
\hline
\end{tabular}

\subsubsection{Idea Shopping}

Idea shopping refers to people's need for structure, order and knowledge. Shoppers are seen to need informative guidance from outside in order to make sense of themselves (Parsons 2002). Here, three main subthemes emerged from the interviews. The first was the motivation to explore new designs and new fashion trends, from Arab and Moslem countries for those adhering to the restrictions and from Western countries for those rejecting them. The second motivation was to attach oneself to liberal societies. This subtheme emerged clearly from interviews with those perceiving Saudi's social and religio-legal restrictions negatively. PRT tells us that people expect certain freedoms, and such behaviour allows them to experience this feeling of freedom. The third motivation was simply to break the restrictions.

The desire to discover new designs existed regardless of hijab index score, but Table 6 demonstrates that consequent behaviour differed. Women with a high religiousness of dress might buy foreign fashions, but they then either tailored them to suit their religious requirements or would never wear them in public, only at female-only gatherings:

I very much love following fashion. Before, I used to follow Lebanese fashion magazines; now, I love to follow fashion through the internet as long as it can fit my religious requirements. I buy fashions that I can remodel later. $05 \mathrm{HL}$ 
Table 6: Religiousness of dress and behaviour associated with the motivation to discover new designs

\begin{tabular}{|c|l|}
\hline $\begin{array}{c}\text { Religiousness } \\
\text { of dress }\end{array}$ & \multicolumn{1}{c|}{ Behaviour } \\
\hline High hijab index & $\begin{array}{l}\text {-Discovering new designs from Moslem countries such as Turkey, } \\
\text { Egypt and Lebanon. } \\
\text {-Discovering new designs from Western websites intending to wear } \\
\text { them at home or among females. }\end{array}$ \\
\hline Low hijab index & $\begin{array}{l}\text { ·Discovering new designs from Western websites to wear in public } \\
\text {-Attaching oneself to liberal societies } \\
\text { ·Breaking the restrictions }\end{array}$ \\
\hline
\end{tabular}

Online shopping allows those who oppose Saudi fashion restrictions to escape to other more consumer-friendly societies providing a sense of freedom. Similarly, this research found strong evidence that highly psychologically reactant women faced with Saudi restrictions were very interested in international brands in general and that the online channel helped them to keep in touch with these more liberal markets. The pressure of the restrictions upon them make even a simple act of online shopping appear as an act of defiance:

I love both browsing and shopping online. It gives me interesting ideas of what the current international fashion lines are. 22LN

The behaviour of such women can be seen to differentiate them from others both by buying distinct fashions instead of buying the international brands available in Saudi Arabia:

I don't buy online from BHS Saudi Arabia. I buy from other European branches of BHS. I never buy from the Saudi shops.30MT

Thus, psychological reactance was often demonstrated in the specific use of the internet to buy "public fashion" from outside Saudi Arabia in order to break the fashion restrictions. However, women attend female only gatherings and parties so fashion is still very important to them, even amongst a minority of those who are very adherent to the religious restrictions:

“...they always see me as a fashion icon at our female parties” 15HHM 


\subsubsection{Fashion Shopping}

Arnold and Reynolds, (2003) describe value shopping as stemming from the competitive desire to win admiration and boost self-esteem. The associated behaviour varied here according to fashion religiousness. Women with a low hijab index were happy to buy Western fashions and wear them unmodified in public, differentiating themselves by buying from international fashion websites. Those who accepted the restrictions but wanted to win the admiration of others also bought Western fashions, but not to be worn as purchased, because this would contravene their accepted modesty level. There is still caché in wearing western brands albeit modified to Saudi religious requirements and such women would customise or tailor their purchases (Albrecht, Jacobs, Retief and Adamski, 2015), their behaviour, therefore still exhibiting system justification. A significant proportion of the interviewees $(26 / 34)$ reported doing so by approaching online tailors to make the garments they had purchased more modest, in line with their religious beliefs, whilst still being unique and distinct. These quotations are from women with medium and high hijab index scores respectively.

I usually can't find the required level of modesty online, so I buy something that can be tailored, then send it to the tailor to fix it. 13MA

I go to international fashion websites. I select what appeals to me and can be customized to fit my religious needs later. I try to buy the best while respecting my religious values. $05 \mathrm{HL}$

Eventually, some women no longer browsed international websites but relied on online tailors to upload international fashion designs, offering to customize them to suit clients' religious needs:

I contacted a good designer who I found on Instagram. I asked her to design fashionable clothes to fit my religious needs. She shows me the designs and we choose one from them. Then she customizes it and makes a new Islamic version for me. 15HM 
Participants who rated highly on religiousness of dress may have had a dual motivation for customisation: fitting their restrictions while also being fashionable, at least in women-only gatherings. As to those who rated less highly on the modified hijab index and who tended to reject dress restrictions, their motivation for customisation and tailoring was more likely to be a desire to distinguish themselves from others.

I love to wear my own designs. When I see a good design, I put my own touches on it and send the new design to my tailor. 20LZ

Women who opposed the fashion restrictions described wearing clothes from non-Muslim countries or personally designed using Instagram, as a symbol both of their rejection of such rules and of being different from their peers in traditional Saudi dress,

I love to design my fashion. I don't enjoy wearing traditional Saudi clothes. I love to be unique and no one else wears what I wear. $20 \mathrm{LZ}$

\section{Discussion and Conclusion}

Restrictive societies will, by definition, create different shopping behaviours from those in liberal Western societies. Western consumers take for granted their freedom to browse for and buy products as they wish and indeed much of the extant literature similarly makes such assumptions of free-choice. In Western markets, online shopping is driven by hedonic and utilitarian motivations (To, Liao and Lin, 2007). Our research is overdue and introduces a new perspective to understand and define shopping motivations in a restrictive society. Due to the lack of prior research in the marketing field, this paper uses theory extensively covered in socio-psychological research, namely system justification theory and psychological reactance theory, to understand how individuals react to and justify restrictions on their behaviour. This research is the first to use such theories in order to understand fashion behaviour in a market dominated by extensive restrictions on women's dress. As summarised in Table Table-7, women whose level of religiosity is lower than that of Saudi society feel 
constrained and react against these restrictions by intentionally wearing their own fashion code regardless of societal restrictions. Psychological reactance theory helps us understand such behaviour. Individuals who feel they are being denied can react against such perceived injustice. Conversely, those whose level of religiosity is equal to or higher than their society tend to justify restrictions by not going shopping alone or avoiding offline shops altogether, shopping online instead. Others adopt an intermediate stance, preferring low religiosity fashion standards but simply accepting the imposed restrictions without reaction or justification; however, when abroad, they change their fashion style to reflect their beliefs. Due to these positions our results tend to concentrate (although not exclusively) on respondents who were either high or low on the hijab index.

Thus, virtual shopping can be seen as a vehicle of liberation and reaction for those who reject such restrictions and as a vehicle of alignment for those who believe in and justify the restrictions. Because of restrictions on Saudi women's movements, those accepting these restrictions argue that online shopping is the best way to buy clothes.

Table 7: Summary of results

\begin{tabular}{|l|l|l|l|}
\hline \multicolumn{2}{|c|}{ High religiousness of dress } & \multicolumn{2}{c|}{ Low religiousness of dress } \\
\hline $\begin{array}{l}\text { System } \\
\text { justification }\end{array}$ & Neutral & Neutral & $\begin{array}{l}\text { Psychological } \\
\text { reactance }\end{array}$ \\
\hline $\begin{array}{l}\text { Utilitarian } \\
\text { motivations: } \\
\text { To accommodate } \\
\begin{array}{l}\text { and to rationalise } \\
\text { the restrictions }\end{array}\end{array}$ & $\begin{array}{l}\text { Hedonic motivations: } \\
\text { To discover new } \\
\text { Islamic fashion and to } \\
\text { distinguish themselves } \\
\text { by designing their own } \\
\text { fashion to be worn in } \\
\text { female company }\end{array}$ & $\begin{array}{l}\text { Hedonic } \\
\text { motivation: } \\
\text { To discover new } \\
\text { Western fashion } \\
\text { trends }\end{array}$ & $\begin{array}{l}\text { To break the } \\
\text { restrictions and to } \\
\text { distinguish themselves } \\
\text { from their peers }\end{array}$ \\
\hline
\end{tabular}

The Western definition of utilitarian motivation involves convenience (Jones, Reynolds and Arnold, 2006), accessibility and cost saving (To et al., 2007); this paper extends the concept to include overcoming the difficulties faced by women in a restrictive society as the fashion culture in Saudi Arabia is wholly dissimilar to that of the West. Three dimensions are added 
to the existing utilitarian definition of convenience: overcoming the difficulties of travelling to the market due to religio-legal restrictions; overcoming the self-interpreted religious restriction on women attending markets; and buying products that social restrictions prevent from being produced in Saudi. It is difficult for those brought up in liberal western democracies to appreciate the restrictions placed upon our sample; by the community and religious police, the legacy of the prohibition against females driving, the need to be accompanied by a male relative and lack of transportation. In addition, avoiding male salesmen in retail outlets cannot be underestimated for conservative women who would rather buy personal products discreetly. It should be noted that the convenience of the web for the western consumer is not completely replicated for the Saudi consumer. Shipping problems are common. On average, delivery takes more than a month, with the possibility that the purchased items will never arrive. The western consumer has been coached by Amazon to expect next-day delivery and would consider the Saudi experience of online shopping to be inconvenient! Many respondents recalled a miserable experience with online shipping. These utilitarian motives extend our knowledge as they would not be considerations in western societies.

Hedonic motivations in liberal societies include exploration of new things (To et al., 2007; Arnold and Reynolds, 2012); again, this paper adds three new dimensions: distinguishing oneself from one's peers; breaking the restrictions; and attaching oneself to other liberal societies. Western literature refers to the freedom accorded by online shopping in that there are no salespeople, no queues and no crowds, but boundless choice (Wolfinbarger and Gilly 2001). In a restrictive society, freedom is defined differently, as buying what you want and not being controlled by how society wants you to dress or the necessity of being chaperoned. Saudi society brings considerable pressure to conform and psychological reactance through online shopping is able to restore a measure of control to certain consumers. The hedonic 
element of purchase for our consumers was reinforced as all purchases were for themselves. There was no discussion amongst respondents of buying online for gifts, possibly due to the stated problems of long and unreliable delivery. Buying the wrong sized item for a relative or friend would prove far more difficult to return. There must therefore be a stronger motivation to shop online in the first place.

Although the literature states that buying from Western countries or choosing products produced locally but carrying the names of Western companies is perceived to be motivated hedonically (Salciuviene, Ghauri, Streder and de Mattos 2010), this research found this not to be always absolutely true. Those who justified the restrictions purchased Western products only when necessary, i.e. for utilitarian rather than hedonic reasons. SJT helps explain why certain individuals are happy to comply with the status quo even when it clearly is against their own personal interest (Jost et al, 2004).

Women, especially the middle-class, buy international fashion in order to attach themselves to neo-liberal markets (Al-Mutawa 2013; Kravets and Sandikci 2014). This research adds another dimension to explain why and how some women buy international brands in restrictive environments. Women manifesting psychological reactance were more hedonically motivated and ready to breach market conformity than those who accepted and justified the restrictions. Reactance theory acts as a reinforcement of such consumers contrary behaviour.

This research, supported by others (Jafari and Sand1kc1, 2016), offers evidence that ideology should be added to the list of factors to be considered in understanding consumer behaviour. International markets are segmented within as well as between cultures and one must understand the diversity of the drivers of consumer behaviour underlying this segmentation, in order to categorise individual consumers not only according to their psychological and social needs and behaviours (Wedel and Kamakura, 2012), but also by their ideologies. El- 
Bassiouny, $(2014$; 2016) believes the tourism market to be segmented by levels of religiosity. This research helps to segment a market not only by well-known demographic, situational or behavioural factors (Dibb, Simkin, Pride and Ferrel, 2005), but also by the level of cultural identity, in line with Sia, Lim, Leung, Lee, Huang and Benbasat, (2009), and by the extent of justification or reactance vis-à-vis existing restrictions, as each segment behaves differently when shopping online for fashion.

Belief in restrictions can be seen as stratified (Kohlberg, 1976). In other words, strong believers might defend their understanding of the restrictions by deeming international brands offensive, thereby avoiding cognitive dissonance. Our research has cast a light on some key differences that lead to online shopping that would not be obvious to a western consumer. According to our respondents, wWestern fashion brands are certainly not fully catering for the market of Muslim female consumers, many, as with our sample, from high GDP countries containing a growing middle class. Such brands are at an advantage in trying to attract Saudi customers as our respondents reported high levels of trust in them. Indeed, there was an avoidance of Saudi companies online in favour of international brands. Branding can replace the need for touch and compensate for possible risk (Hongyoun and Kim, 2009; González-Benito et al., 2015) and western organisations should concentrate on brand building on platforms such as Instagram in order to attract Saudi consumers. However, the industry can benefit by knowing how strongly many Muslim women feel towards their culture. Designers of e-marketing should avoid over-revealing images of women and exposed skinnudity. Such images will discourage these women from returning to a website or social media post or even from continuing browsing and shopping. Indeed, the finding that many women purchase online and then tailor their purchases demonstrates the opportunity for western brands to hire individuals who are expert in the more modest needs of not just Saudi, but female Muslim consumers more generally. 
In developing research in a market like Saudi it would be interesting to probe deeper into higher order reasons behind consumer behaviour, through, for example means-end analysis. Clearly the theories that we have used to explain behaviour (SJT and PRT) provide the opportunity to study the longer term or higher order goal of consumers perhaps relating to their wider freedom or indeed fear of the unknown and hence the preservation of the status quo. 


\section{References}

Ahmed, L. (1992), Women and gender in Islam: Historical roots of a modern debate, Yale University Press.

Albrecht, M., Jacobs, B., Retief, A. \& Adamski, K. (2015), "The role of important values and predominant identity in the dress practices of female Muslim students attending a South African university", Clothing and Textiles Research Journal, vol. 33, No. 4, pp. 1-17.

Alhojailan, M.I. (2012), "Thematic Analysis: A critical review of its process and evaluation", WEI International European Academic Conference, p. 8.

Al-Mutawa, F. (2013), "Consumer-generated representations: Muslim women recreating Western luxury fashion brand meaning through consumption", Psychology \& Marketing, vol. 30, no. 3, pp. 236-246.

Al-Rasheed, M. (2013), A most masculine state: Gender, politics and religion in Saudi Arabia, Cambridge University Press, Cambridge.

Altemeyer, B. (2002), "Dogmatic behavior among students: Testing a new measure of dogmatism", The Journal of Social Psychology, vol. 142, no. 6, pp. 713-721.

Arnold, M.J. \& Reynolds, K.E. (2003), "Hedonic shopping motivations", Journal of Retailing, vol. 79, no. 2, pp. 77-95.

Arnold, M.J. \& Reynolds, K.E. (2012), "Approach and avoidance motivation: Investigating hedonic consumption in a retail setting", Journal of Retailing, vol. 88, no. 3, pp. 399-411.

Baamer, Y. (2015), Banning fashion shows in Saudi Arabia. Available: http://alwatan.com.sa/Nation/News Detail.aspx?ArticlelD=225566\&CategorylD=309/2015.

Babin, B.J., Darden, W.R. \& Griffin, M. (1994), "Work and/or fun: measuring hedonic and utilitarian shopping value", Journal of Consumer Research, vol. 20 no. 4, pp. 644-656.

Braun, V. \& Clarke, V. (2006), "Using thematic analysis in psychology", Qualitative Research in Psychology, vol. 3, no. 2, pp. 77-101.

Brehm, J.W. (1966), A theory of psychological reactance, Oxford Academic Press, Oxford.

Budner, S. (1962), "Intolerance of ambiguity as a personality variable.", Journal of Personality, vol. 30, pp. 29-50.

Charmaz, K. (2006), Constructing grounded theory: A practical guide through qualitative analysis, Sage, London.

Compeau, L.D., Monroe, K.B., Grewal, D. \& Reynolds, K. (2015), "Expressing and defining self and relationships through everyday shopping experiences", Journal of Business Research, vol. 69, no. 3, pp. 1035-1042. 
Cooper, J. (2007), Cognitive dissonance: 50 years of a classic theory, Sage, London.

Deif, F. (2008), Perpetual minors: Human rights abuses stemming from male guardianship and sex segregation in Saudi Arabia, Human Rights Watch, London.

Dibb, S., Simkin, L., Pride, W.M. \& Ferrell, O. (2005), Marketing: Concepts and strategies, Houghton Mifflin, Boston.

Dubois, A. \& Gadde, L. (2002), "Systematic combining: an abductive approach to case research", Journal of Business Research, vol. 55, no. 7, pp. 553-560.

El-Bassiouny, N. (2014), "The one-billion-plus marginalization: Toward a scholarly understanding of Islamic consumers", Journal of Business Research, vol. 67, no. 2, pp. 42-49.

El-Bassiouny, N. (2016), "Where is 'Islamic marketing' heading?: A commentary on Jafari and Sandikci's (2015) 'Islamic' consumers, markets, and marketing", Journal of Business Research, vol. 69, no. 2, pp. 569-578.

Fabre, C., Malauzat, A-L, Sarkis, C., Dhall, T. \& Ghorra, J. (2019), E-Commerce in MENA:

Opportunity Beyond the Hype, https://www.bain.com/insights/ecommerce-in-MENAopportunity-beyond-the-hype/ accessed on 6/1/20. Francis, L.J. (2001), "Christianity and dogmatism revisited: A study among fifteen and sixteen year olds in the United Kingdom", Religious Education, vol. 96, no. 2, pp. 211-226.

Farrag, D.A. \& Hassan, M. (2015), "The influence of religiosity on Egyptian Muslim youths' attitudes towards fashion," Journal of Islamic Marketing, vol. 6, no. 1, pp. 95-108.

Flavian, C., Gurrea, R. \& Orus, G. (2020), Combining channels to make smart purchases: The role of webrooming and showrooming, Journal of Retailing and Consumer Services, 52.

Francis, L. J. (2001), "Christianity and dogmatism revisited: A study among fifteen- and sixteen-year olds in the United Kingdom", Religious Education, vol. 96, no. 2, pp. 211-226.

Glaser, B.G. \& Strauss, A.L. (2009), The discovery of grounded theory: Strategies for qualitative research, Transaction Books, New Jersey.

Göbel, M., Schneider, A. \& Thomas, T. (2010), "Consumption behavior and the aspiration for conformity and consistency.", Journal of Neuroscience, Psychology, and Economics, vol. 3, no. 2, pp. 83.

Greenberg, J. (2014), Obeidallah: Saudi Arabia is the only Muslim nation where women can't drive. Available: http://www.politifact.com/punditfact/statements/2014/oct/07/deanobeidallah/obeidallah-saudi-arabia-only-muslim-nation-where-w/.

Grewal, D., Roggeveen, A.L. \& Nordfâlt, J. (2017), The future of retailing, Journal of Retailing, 93(1), $1-6$.

Griffin, M., Babin, B.J. \& Modianos, D. (2000), "Shopping values of Russian consumers: the impact of habituation in a developing economy", Journal of Retailing, vol. 76, no. 1, pp. 33-52. 
Hagberg, J., Sundstrom, M. \& Egels-Zandén, N. (2016), The digitalization of retailing: an exploratory framework, International Journal of Retailing and Distribution Management, 44 vol. 7, pp. 696712.

Hassan, S.H. \& Harrun, H., (2016), "Factors influencing fashion consciousness in hijab fashion consumption amongst hijabistas," Journal of Islamic Marketing, vol. 7, no. 4, pp.476-494. Hemetsberger, A. \& Weinberger, R. (2012), "In Pursuit of Being Different.", Advances in Consumer Research, vol. 40, pp. 502-509.

Hood, R., Spilka, B., Hunsberger, B. \& Gorsuch, R. (1996), Religion, coping, and adjustment, In Spilka, B., Hood, R.W., Hunsberger, B. \& Gorsuch, R. (eds.), The psychology of religion: An empirical approach (pp. 377-405), Guilford Press, New York.

Hussein, A. (1953), "The role of women in social reform in Egypt", The Middle East Journal, vol. 7, no. 4 , pp. 440-450.

Jafari, A. \& Sandıkcı, Ö, (2016), "The ontological pitfalls of Islamic exceptionalism: A re-inquiry on El-Bassiouny's $(2014,2015)$ conceptualization of 'Islamic marketing'", Journal of Business Research, vol. 69, no. 3, pp. 1175-1181.

Jones, M.A., Reynolds, K.E. \& Arnold, M.J. (2006), "Hedonic and utilitarian shopping value: Investigating differential effects on retail outcomes", Journal of Business Research, vol. 59, no. 9, pp. 974-981.

Jost, J.T. \& Hunyady, O. (2003), "The psychology of system justification and the palliative function of ideology", European review of social psychology, vol. 13, no. 1, pp. 111-153.

Jost, J. T. \& Hunyady, O. (2005), "Antecedents and consequences of system-justifying ideologies", Current Directions in Psychological Science, vol. 14, no. 5, pp. 260-265.

Jost, J.T., Banaji, M.R. \& Nosek, B.A. (2004), "A decade of system justification theory: Accumulated evidence of conscious and unconscious bolstering of the status quo", Political Psychology, vol. 25, no. 6, pp. 881-919.

Kadirov, D., Allayarova, N. \& Boulanouar, A.W. (2016), "Transformation as reversion to fitrah: Muslim Māori women's self-transformation through reflexive consumption", Journal of Business Research, vol. 69, no. 1, pp. 33-44.

Kay, A.C., Gaucher, D., Napier, J.L., Callan, M.J. \& Laurin, K. (2008), "God and the government: testing a compensatory control mechanism for the support of external systems.", Journal of Personality and Social Psychology, vol. 95, no. 1, pp. 18.

Kay, A.C., Gaucher, D., Peach, J.M., Laurin, K., Friesen, J., Zanna, M.P. \& Spencer, S.J. (2009), "Inequality, discrimination, and the power of the status quo: Direct evidence for a motivation to see the way things are as the way they should be", Journal of Personality and Social Psychology, vol. 97, no. 3, pp. 421-434.

Kassim, N.M. \& Zain, M.M., (2015), "Quality of lifestyle and luxury purchase inclinations from the perspective of affluent Muslim consumers," Journal of Islamic Marketing, vol.7, no. 1, pp.96119. 
Khare, A., Parveen, C. \& Mishra, A. (2012), "Influence of normative and informative values on fashion clothing involvement of Indian women", Journal of Customer Behaviour, vol. 11, no. 1, pp. 9-32.

Knight, C. G., Tobin, S. J. \& Hornsey, M. J. (2014), "From fighting the system to embracing it: control loss promotes system justification among those high in psychological reactance", Journal of experimental social psychology, vol. 54, no. 5, pp. 139-146.

Kohlberg, L. (1976), Moral stages and moralization: The cognitive-developmental approach, In Likona, T. (ed.) Moral development and behavior: Theory, research, and social issues (pp. 3153), Holt, Rinehart \& Winston, New York.

Kravets, O. \& Sandikci, O. (2014), "Competently ordinary: New middle class consumers in the emerging markets", Journal of Marketing, vol. 78, no. 4, pp. 125-140.

Kwon, S.J. \& Chung, N. (2010), "The moderating effects of psychological reactance and product involvement on online shopping recommendation mechanisms based on a causal map", Electronic Commerce Research and Applications, vol. 9, no. 6, pp. 522-536.

Laurin, K., Kay, A.C. \& Fitzsimons, G.J. (2012), "Reactance versus rationalization: Divergent responses to policies that constrain freedom", Psychological Science, vol. 23, no. 2, pp. 205209.

Laurin, K., Kay, A.C., Proudfoot, D. \& Fitzsimons, G.J. (2013), "Response to restrictive policies: Reconciling system justification and psychological reactance", Organizational Behavior and Human Decision Processes, vol. 122, no. 2, pp. 152-162.

Lee, A.S. \& Hubona, G.S. (2009), "A scientific basis for rigor in information systems research", MIS Quarterly, vol. 33, no. 2, pp. 237-262.

Lee, G., Lee, J. \& Sanford, C. (2010), "The roles of self-concept clarity and psychological reactance in compliance with product and service recommendations", Computers in Human Behavior, vol. 26 , no. 6 , pp. 1481-1487.

Lim, W.M. (2014), "Understanding the influence of online flow elements on hedonic and utilitarian online shopping experiences: A case of online group buying", Journal of Information Systems, vol. 28 , no. 2 , pp. 287-306.

Moaddel, M. (2013), The birthplace of the Arab Spring: Values and perceptions of Tunisians. National Consortium for the Study of Terrorism and the Response to Terrorism (START), College Park, University of Maryland.

Neslin, S.A., Jerath, K., Bodapati, A. et al. (2014), The interrelationships between brand and channel choice. Marketing Letters, 25, 319-330.

Ong, B.K. (2012), "Grounded Theory Method (GTM) and the Abductive Research Strategy (ARS): a critical analysis of their differences", International Journal of Social Research Methodology, vol. 15 , no. 5, pp. 417-432. 
Parker, R.S., Hermans, C.M. \& Schaefer, A.D. (2004), "Fashion consciousness of Chinese, Japanese and American teenagers", Journal of Fashion Marketing and Management, vol. 8, no. 2, pp. 176-186.

Parsons, A.G. (2002), "Non-functional motives for online shoppers: Why we click", Journal of Consumer Marketing, vol. 19, no. 5, pp. 380-392.

Salciuviene, L., Ghauri, P.N., Salomea Streder, R. \& De Mattos, C. (2010), "Do brand names in a foreign language lead to different brand perceptions?", Journal of Marketing Management, vol. 26, no. 11, pp. 1037-1056.

Sarkar, A. (2011), "Impact of utilitarian and hedonic shopping values on individuals' perceived benefits and risks in online shopping", International Management Review, vol. 7, no. 1, pp. 5865.

Saroglou, V. (2002), "Religion and the five factors of personality: A meta-analytic review", Personality and Individual Differences, vol. 32, no. 1, pp. 15-25.

Scarpi, D., Pizzi, G. \& Visentin, M. (2014), "Shopping for fun or shopping to buy: Is it different online and offline?", Journal of Retailing and Consumer Services, vol. 21, no. 3, pp. 258-267.

Sebald, A.K. \& Jacob, M. (2019), "What help do you need for your fashion shopping? A typology of curated fashion shoppers based on shopping motivations," European Management Journal, vol. 38, pp. 319-334.

Sia, C.L., Lim, K.H., Leung, K., Lee, M.K.O., Huang, W.W. \& Benbasat, I. (2009), "Web Strategies to promote internet shopping: Is cultural-customization needed?", MIS Quarterly, vol. 33, no. 3, pp. 491-512.

Statista.com (2020), E-Commerce in Saudi Arabia, https://www.statista.com/outlook/243/110/ecommerce/saudi-arabia accessed 6/1/20.

Swami, V., Miah, J., Noorani, N. \& Taylor, D. (2014), "Is the hijab protective? An investigation of body image and related constructs among British Muslim women", British Journal of Psychology, vol. 105, no. 3, pp. 352-363.

Talukdar, D., Sudhir, K. \& Ainslie, A. (2002), "Investigating new product diffusion across products and countries", Marketing Science, vol. 21, no. 1, pp. 97-114.

To, P., Liao, C. \& Lin, T. (2007), "Shopping motivations on Internet: A study based on utilitarian and hedonic value", Technovation, vol. 27, no. 12, pp. 774-787.

To, P. \& Sung, E. (2015), "Internet shopping: A study based on hedonic value and flow theory", International Journal of Social, Behavioral, Educational, Economic and Management Engineering, vol. 9, no. 7, pp. 2115-2118.

Tolaymat, L.D. \& Moradi, B. (2011), "US Muslim women and body image: Links among objectification theory constructs and the hijab.", Journal of Counseling Psychology, vol. 58, no. 3, pp. 383. 
Variyar, M. (2015), , Saudi Arabia bans fashion shows. Available: http://www.ibtimes.co.in/saudiarabia-bans-fashion-shows-63462809/2015].

Venkatesan, M. (1966), "Experimental study of consumer behavior conformity and independence", Journal of Marketing Research, vol. 3, pp. 384-387.

Wao, H.O., Dedrick, R.F. \& Ferron, J.M. (2011), "Quantitizing text: using theme frequency and theme intensity to describe factors influencing time-to-doctorate", Quality \& Quantity, vol. 45, no. 4, pp. 923-934.

Wedel, M. \& Kamakura, W.A. (2012), Market segmentation: Conceptual and methodological foundations, Springer Science \& Business Media, Berlin.

Welsh, D. H. B., Memili, E., Ouchi, M., \& Kaciak, E. (2014). Japanese women entrepreneurs: Implications for family firms. Journal of Small Business Management, vol. 52, no.2, pp. 286305. doi:10.1111/jsbm.12099

Wicklund, R.A. \& Brehm, J.W. (1976), Perspectives on cognitive dissonance, Psychology Press. Hillsdale, NJ.

Wolfinbarger, M. \& Gilly, M.C. (2001), "Shopping online for freedom, control, and fun", California Management Review, vol. 43, no. 2, pp. 34-55.

World Economic Forum (2018), The Global Gender Gap Report, 2018. Geneva, Switzerland.

Xu, Y. \& Paulins, V.A. (2005), "College students' attitudes toward shopping online for apparel products: Exploring a rural versus urban campus", Journal of Fashion Marketing and Management, vol. 9, no. 4, pp. 420-433. 